\title{
The didactics of vocational Bildung: how stories matter in VET research
}

\section{Ruhi Tyson}

To cite this article: Ruhi Tyson (2016) The didactics of vocational Bildung: how stories matter in VET research, Journal of Vocational Education \& Training, 68:3, 359-377, DOI: 10.1080/13636820.2016.1213762

To link to this article: http://dx.doi.org/10.1080/13636820.2016.1213762

曲 Published online: 05 Aug 2016.

6 Submit your article to this journal

LIII Article views: 162

Q View related articles $\asymp$

View Crossmark data $₫$ 


\title{
The didactics of vocational Bildung: how stories matter in VET research
}

\author{
Ruhi Tyson \\ Department of Education, Stockholm University, Stockholm, Sweden
}

\begin{abstract}
In the research on education, the field roughly covered by the concept of Bildung has seen a wide-ranging discussion philosophically but less has been said and done from an empirical and vocational perspective. Bildung includes matters such as: formation of character, ethical and aesthetic knowledge/capability, capacity for wise deliberation and reflection as well as the development of personal autonomy. The focus here is on how narratives about teaching and curricula, both enacted and experienced, can be used to articulate significant aspects of Bildung-related practical knowledge. The empirical basis for this draws on a variety of narrative sources. By presenting, comparing and discussing narratives, it will be argued that there is a number of Bildung-related educational matters, not least in vocational education and training, where a narrative articulation can contribute. These can be differentiated in at least five groups: enriching knowledge of vocational tasks; conceptual development and critical reflection; advancement of practice; development of 'practice fields' and the articulation of patterns of vocational Bildung affordances. In distinguishing these different ways in which vocational Bildung as a form of practical knowledge can be enriched through narrative studies, the article contributes to our capacity for doing systematic research in the subject area.
\end{abstract}

\section{ARTICLE HISTORY}

Received 13 December 2015 Accepted 15 June 2016

\section{KEYWORDS}

Teacher training; philosophy of VET; curriculum innovation; pedagogy; vocational education and training

\section{Introduction}

Vocational education and training (VET) is, to a large degree, a matter of teaching skills and the knowledge needed to perform vocational ${ }^{1}$ tasks. However, it is also about educating reflective practitioners (Schön 1983, 1987), supporting moral development and vocational ethics (Corsten and Lempert 1997; Tyson 2015b) and educating for the development of key qualifications (Brater et al. 1988; UNESCO 2005). These latter issues have been repeatedly argued on a philosophical or policy level and it has been established that the major part of this takes place in conjunction with skill-training and cannot be separated from it (Rauner and Bremer 2004). There has been less work devoted to examining how such educational processes are encouraged and enacted, i.e. their practical (in the sense of being contextdependent and based in experience) didactical aspects. Furthermore, although theorising about narratives as expressions of practical knowledge in a general sense is not uncommon 
(e.g. Gallagher 2013; Worth 2008), empirical studies aiming at documenting such practical knowledge in a systematic way seem rare. A discussion focused on the plurality of ways in which such stories can contribute to research and practice could therefore be an important contribution to a more differentiated and expansive research effort.

In previous work (Tyson 2015a), I have suggested that the concept of Bildung has much to offer here as a way of doing empirical research into several of the above-mentioned fields with a didactical perspective in mind. The focus has been on ways to afford vocational Bildung and how to understand this as a form of practical didactical knowledge on the part of teachers and in the making of curricula. That inquiry was developed through an extensive educational biography centred on bookbinding, gilding and engraving master Mr. Wolfgang B. with whom I was once an apprentice bookbinder. This research is now complemented with some further studies in order to elaborate an aspect of the case that was left less explicit, namely the different kinds of Bildung-narratives that emerged from it. The argument here will be that the various case narratives documented in these studies work as articulations of practical knowledge related to vocational Bildung and that they demonstrate a spectrum of overlapping contributions to practice and research. This, in turn, suggests that research into what is tentatively called narratively articulated vocational Bildung didactics has the potential to contribute to practice and research in a number of significant ways categorised as: enriching knowledge of vocational tasks; conceptual development and critical reflection; advancement of practice; development of 'practice fields' and the articulation of patterns of vocational Bildung affordances.

In what follows I will begin with a brief introduction to the philosophy of Bildung and what it can mean when we speak of vocational Bildung. I will then go on to discuss Bildung as it relates to the narrative articulation of practical knowledge, how this relates to didactics and the various pitfalls that exist when we use stories as sources of knowledge. After this I will go on to discuss the case narratives and how they shed light on the above differentiations rounding things out with some concluding remarks.

\section{Bildung}

Bildung is an educational concept commonly used in the German-speaking world as well as in the Nordic countries. Its most literal translation would be formation or making-an-image-of. It is similar to liberal education in its emphasis on education as something that expands one's horizons and shapes one's character. However, Bildung is a concept with a wider background, not least drawing from the German enlightenment philosophers Kant, Goethe, Schiller and Humboldt (Rittelmeyer 2012). From these diverse sources the philosophy of Bildung has come to emphasise the development of personal autonomy, aesthetic and ethical education, the development of character or virtue and wide-ranging generalist knowledge (Klafki 2000; Rittelmeyer 2012). To be clear, Bildung is also often used in the more general sense of education and this gives rise to interesting tensions in German literature on Bildung since many texts thereby acquire an implicit double meaning.

At the centre of the following argument is the close relationship between Bildung as philosophy and biographical experiences. From Goethe's novel Wilhelm Meister onwards, there has been a tradition of connecting Bildung with a person's biographical trajectory towards maturity, autonomy, moral character, aesthetic sensibility, experience and similar characteristics. This opens the otherwise largely philosophical conversation about Bildung 
to empirical, biographical, studies (cf. Meyer 2009; Trautmann 2004; Tyson 2015a). Such studies fundamentally rest on the understanding that educational processes and contents that are remembered as biographically decisive (critical incidents) are basically descriptions of Bildung. This might not cover everything we can understand when talking about Bildung, but it has the advantage of not qualifying in advance what Bildung contents and processes are, i.e. one can ask about important/memorable events in a person's educational biography without the involvement of Bildung as a concept. This biographical and open-ended philosophical conception of Bildung supports the argument for remaining with the term and, in my view, outweighs the drawback of it being somewhat unwieldy in English. Furthermore, extensive biographical studies can serve as explorative studies of Bildung, where elements and processes are surfaced, which can then lead to more focused narrative studies of Bildungrelated episodes or processes in which questions more specific than, 'what do you remember from your vocational education that has remained as an important event for your subsequent life' are asked.

Also, and this is best stated upfront, Bildung is concept oriented more towards a normative aim of research than towards registering social and biographical processes. With this I am agreeing with those scholars who argue that educational and social research is fundamentally a normative endeavour where it is not just a matter of examining what is, but also of thinking about how this could become more transparent to human flourishing (e.g. Biesta 2013; Flyvbjerg 2001; Hinchliffe 2004; Laszlo et al. 2012).

\section{Vocational Bildung}

If we return for a moment to the initially mentioned issues in VET such as reflective practice, vocational ethics and key qualifications ${ }^{2}$ there is a significant overlap between these and various areas in the conceptual field of Bildung. The development of vocational ethics and virtue, for example, can be understood as aspects of vocational Bildung given the concept of Bildung outlined above. This overlap becomes particularly fruitful as a venue for empirical research when it is brought into connection with Bildung as a biographical process that is possible to study through biographical cases. It might seem to be a drawback to discuss these issues as a matter of vocational Bildung rather than as issues of vocational ethics, specified key qualifications, etc. but the richness and complexity of Bildung as concept can support the elaboration of less fully theorised aspects of VET (for instance, the possible relevance of aesthetic Bildung in VET). The overlap is also present in the relative ambiguity of these kinds of practical knowledge (further discussed below).

Vocational Bildung might seem a foreign concept, especially since, from Plato through Humboldt, one perspective within the tradition has been to contrast Bildung with vocational training. Bildung is then associated with the educated aristocracy (through birth or inherent talent) and understood as a general formation and cultivation of character and, mostly, humanistic knowledge. VET is then opposed to this as that education which aims at instrumental training, characterised as illiberal and narrow, for the masses of people destined to be servants rather than leaders. Such perspectives have done much to discredit the whole idea of Bildung making it appear elitist and divorced from more worldly practical matters (Brater et al. 1988; Thompson 2006).

This is not the whole picture, however, there have been other ways of understanding Bildung that do not so blatantly glorify the philosophers' trade as the template for Bildung 
in general. Goethe and Schiller lean towards the artist and aesthetics as an ideal and educators such as Pestalozzi and Kerschensteiner argued both philosophically and through practical initiatives for Bildung as a process that involves mental and manual labour.

During the twentieth century, there has been a lively philosophical debate in Germany (culminating in several experimental school initiatives) over the contents, processes and possibilities of vocational Bildung, i.e. Bildung as principle and objective of vocational education (Blankertz and Gruschka 1974; Edding, Mattern, and Schneider 1985; Fintelmann 1990; Gonon 2002; Kerschensteiner 1912; Lange et al. 2001). A major part of this has been in the context of craft vocational education, the craftsman being taken as the paradigmatic example of Bildung in vocational contexts, something that holds also when we consider the wider discussion that has been going on over the past few decades where similar issues are considered without being overtly situated in the framework of Bildung (e.g. Crawford 2009; Dormer 1994; Sennett 2008). With few exceptions (cf. Gessler [1988] for a good example of one such exception) this has remained a predominantly philosophical discussion incorporating examples along the way mostly in an illustrative fashion. The argument here is that a more empirical focus has much to offer. One way of approaching this is to combine an interest in vocational Bildung with a narrative approach to practical knowledge to which I turn next.

\section{Narratives of Bildung as articulations of practical knowledge}

When considering narratives of Bildung processes, contents and experiences in relation to practical knowledge we enter into a conceptually difficult area. To begin with practical knowledge can be characterised as based in personal experience, extensive practice and a capacity to adapt to changing situations (cf. e.g. Dunne 1993; Schön 1983). This is the basic reason why narratives can be used to express practical knowledge, a story remains with a specific situation or event rather than decontextualising it in order to say something general. There are numerous fields of practical knowledge where narratives are hardly significant as expressions of that knowledge and where technical manuals of various kinds are more relevant. However, there are also fields of practical knowledge that are less easy to systematically explore because the actions that constitute excellence in that field are difficult or impossible to observe, the processes being largely interior to the participants, unpredictable and/or stretching over longer periods of time. Often, these same actions contain streaks of imagination and creativity (Schön calls it artistry [1983, 1987]) that contribute to lessening the value of manuals and general guidelines because it remains unclear to practitioners how to enact a general idea in an ambiguous concrete situation. All of these issues are, at least in part, present in teaching as an enactment of Bildung affordances (i.e. teaching that understands itself as including more than subject teaching) including matters such as moral action or leadership. All of these, in addition, are largely vocational in the sense that leadership means different things to a preschool teacher and the manager of a factory. Furthermore, all are teachable to some degree although as with all practical knowledge personal practice and experience cannot be dispensed with. With teachable I mean both in the sense of being a teacher in the field and being a student who is taught (although Schön [1987], would probably insist on calling these actions coaching rather than teaching). Here then, is the central issue and the role of narratives as part of solving it. The problem is that these and other important aspects of vocational practical knowledge tend to remain personal, i.e. I know what I know of teaching and affording vocational Bildung based on my immediate role 
models together with the experiences I have had at a select few institutions and cultural contexts. I cannot, for the most part, do as any craftsperson could and compare my techniques with those of others, look at what my peers and predecessors have made and, at least in part, reconstruct how. The objection that there are many books written on good leadership, or moral action as virtue and practical wisdom rather serves to emphasise the present argument given that, for the most part, such books contain a wealth of general statements, sometimes together with some illustrative examples from practice. It is precisely the difficulty of using these general propositions in concrete, unique situations that calls for studies in narratively articulated vocational Bildung didactics.

When a teacher enacts a Bildung affordance successfully, such as deliberating wisely on how to solve a conflict, these processes leave little material trace. This puts practitioners in a situation where repeatedly reinventing the wheel is almost unavoidable and where local knowledge traditions have difficulty being made available to others as well as subjected to critical and systematic inquiry. This is all the more so since a critical perspective emanating largely from more general, propositional knowledge is difficult to bring to bear on practice given that practice can be interpreted to fit several, sometimes conflicting, theories. In other words, critical inquiry can be substantially strengthened by narratives from other, dissimilar, practices. The argument then, is that systematic attention to the stories people tell of successfully enacted Bildung affordances, and possibly other fields of practice, open these up to critical inquiry as well as more systematic and reflective professional development.

Why success-stories? We might consider each story a single case study and as Larsson (2009) has argued cases can be used for pattern recognition and Flyvbjerg (2006) lists four kinds of information-oriented cases: extreme/deviant cases, maximum variation cases, critical cases and paradigmatic cases. Furthermore, in the present context, if we have a larger group of narratives that relate to the same issue but in significantly different ways there is the possibility of mapping a 'field of practice'. In all of these contexts narrative cases that are unusually successful are more likely to be relevant. They are more likely to reveal patterns hitherto seldom considered, to question established norms of action and behaviour and to surface a wide expanse of practice. They are also more likely to yield extreme and paradigmatic cases of rich practice, especially in areas where everyday practice is characterised by problems and difficulties. The importance of success-stories is also a general issue when doing research into educational practice (or the practice of leadership, etc.) since this practice is not neutral. It has no fixed baseline from which to proceed (at least not until research such as this has been conducted) and since we are beings who interpret our environment and modify our actions each narrative is a potential contributor to this interpretation. This holds for both researchers and practitioners. By asking: 'what was surprisingly or exceptionally successful?' we challenge what we take for granted and we expand on what may be considered possible in a field of practice. Furthermore, we enrich that field with new varieties of potential action. No single narrative can provide other than provisional answers and what might be considered successful will change according to circumstance and with time. Systematically, gathering such narratives over longer time periods might result in the initial narratives feeding into the practice of teachers and leading to new narratives that are even richer than the initial ones. For every generation that leaves work as leaders, teachers, etc. a significant amount of their practical knowledge leaves with them when it could have been different. 


\section{Narratives, didactics and Bildung}

Didactics, or Didaktik in German, is commonly defined as the what, how and why of teaching or the relationship between student, teacher and subject (Uljens 1997). This is close to conceptions such as the enacted and experienced curriculum (Billett 2011), or Shulman's pedagogical content knowledge (Shulman 2004). In the present context the relevant point is that a significant part of didactics is a form of craft-like practical knowledge that a teacher has. With this I mean that it cannot be learnt as a form of theoretical knowledge that can then be applied to practice but rather that it is a complex combination of experience, theory and skill (cf. Dunne 1993; Schön 1987; Tyson 2015a). This, in turn, is connected to an understanding of practice as continuously presenting the practitioner with new variations of situations effectively limiting the value of formal rules and necessitating the use of interpretation and imagination (Schön 1987; Tyson 2016a).

One issue to bear in mind is that narrative research in vocational Bildung didactics can focus on two different kinds of story: stories teachers tell about affording vocational Bildung to students (or students about experiencing it) and stories practitioners tell about important vocational Bildung experiences in their practice. Both can be didactically relevant in the various ways explained in the following sections.

It is not especially common to find didactically relevant research into the teaching and experiencing of vocational Bildung, which is perhaps not surprising since it is not usually an observable process. This is where narrative studies (of which biographical studies are a subspecies) enter into the picture. Narratives, owing to their ability to remain close to experience, are a way of articulating practical knowledge that otherwise tends to remain non-verbal and thus difficult to communicate. Having a narrative interest in the practical knowledge of teachers has its forebears. However, connecting this empirically with Bildung as a teaching action seems uncommon (Tyson 2016a). Because Bildung is a biographical process there are few other ways to articulate how an education has afforded such experiences than in narratives. I use the term 'afforded' explicitly here since Bildung isn't something that one can fully plan for, thus the best we can hope for is the description of actions and environments that have been especially rich in affording Bildung. This brings me to the conceptual centre of the argument: practical knowledge can be articulated and thus passed on to others and made public through narratives. Teaching aiming at affording Bildung is a practical knowledge-form and can thus be narratively expressed (this has several dimensions beyond what I have space to elucidate here, cf. Tyson [2014, 2015a, 2016a]).

There are, however, several issues with narrative knowledge forms that need to be dealt with. First among these is the Scylla and Charybdis of storytelling: arbitrary and literal interpretations, respectively. Literalness implies a lack of imagination when working with a narrative and thus a rigid repetition of it down to its details when it is used as a source for further action. It is common among beginners who are inexperienced and therefore search for rules to guide them echoing similar points made by Schön $(1983,1987)$ and Dreyfus and Dreyfus (1986). Being arbitrary means paying insufficient attention to the details of a narrative, to allow one's imagination to morph into fancy as the poet Coleridge would say (Barfield 2014). Interpretation requires a certain fidelity towards the meaning of a story. Such arbitrariness can to some extent be countered by a requirement to make explicit the principles or general ideas that are enacted in the narrative. 
Second, there are issues with taking a story out of its oral or experiential context and writing it down thereby significantly decontextualising and depersonalising it. There are no perfect remedies for this. One way of preserving some of the personal character of a narrative is by situating it in a larger biography thereby limiting the difficulty of interpreting shorter episodes. Perhaps the most effective way of dealing with this is by tackling the issue head on and increasing the conceptual rigour with which one analyses and comprehends the narratives.

Third, and connected to the second point, any practice that is mostly embodied, disseminated through stories and repetition and where much of it is highly personalised (all of which fit teaching just as well as traditional crafts) has an inherent tendency to be conservative (Gallagher 2013). So do the stories told about it in a naïve setting, i.e. when reflective questioning and searching has not been made part of it. To counter this, a reflective storytelling needs to be cultivated where counter-narratives are actively sought out and where there is a conscious effort to consider the larger discourse in which a narrative might fit.

Fourth, is the risk of anecdotalism, which means a narrative is handled gratuitously and superficially, often by way of making a general point (cf. Griffiths and Macleod 2008). The problem is compounded by the allure that a 'good story' can exercise in the sense that it touches an emotional part of us that can inhibit judgement. This habit of generalising from narratives of unique cases is perhaps one of the main reasons it is neglected as a form of knowledge since it has caused such extensive damage in the past and continues to do so in the present. Once more there are no simple remedies to this. One is implicit in the research aim proposed here, a systematic collection of narratives that if pursued extensively can yield success-narratives relating to the same issue but articulating opposing ways of dealing with it. Another is, to repeat myself, a rigorous approach to the philosophical or conceptual development of Bildung, narrative, didactics and practical knowledge in order to strengthen precisely that rational aspect of one's being that is needed in order to avoid making hasty and unwarranted judgements.

Fifth, there is often insufficient attention paid to what a narrative as articulation of practical knowledge can do (cf. Flyvbjerg [2006] and Thomas [2010] on case studies, almost any kind of case study being possible to understand as a narrative). I have discussed this from a theoretical perspective above and will move now to the empirical part of the article: differentiating some of the ways that narratively articulated vocational Bildung didactics can contribute to research and practice.

\section{Some considerations on methodology and research design}

There is need here for a brief discussion on method and research design when conducting this kind of narrative didactical research. There are several ways to conduct such inquiry; it can be done as action research in the field of professional development, as part of courses in vocational teacher education, as part of the courses that vocational students or apprentices take and as biographical research.

Of the three examples presented the first two are the results of biographical interviews and as such represent more of a collaboration between the counterpart and myself as interviewer. The first narrative is taken from a larger study on the vocational education biography of craftmaster Wolfgang B. (cf. Tyson 2015a). The second narrative is from an unpublished study, part of which consisted of interviews made with craft-teachers and the stories they 
told about memorable educational interventions. Both were conducted as a series of interviews in Swedish which were then transcribed and translated as well as receiving some further editing since the contents of the conversations are more important than the exact form.

The third example is taken from one of three case studies conducted between the spring of 2015 and winter of 2016 in which students enrolled in various teacher programmes wrote stories about vocational Bildung experiences as part of didactics courses. One, reported in Tyson (2016a) was with students at an after-school care teacher programme, one with students at a vocational teacher programme and the third with students at a nurse instructor programme (the latter two are both aimed at qualifying active practitioners and nurses for teaching in Swedish upper secondary vocational programmes). The first two are discussed only briefly in the following with focus being on a narrative taken from the nurse instructor programme.

Writing narratives has strengths and weaknesses. A substantial drawback when asking people to write didactically relevant stories of vocational Bildung is that many are simply not used to writing stories. In conversation the stories we tell are usually co-constructed, the listener assisting the teller in contextualising and adding detail as needed. It is also more difficult to get longer stories given the amount of work that goes into writing compared to conversations. Another complication is that in conversation a researcher can ask follow-up questions, elicit elaborations when a person touches on a relevant subject but doesn't explore it fully, etc. The written assignments tend to be more final. However, it is hardly possible to cover much ground in this kind of research if we rely exclusively on interviewing, and having whole cohorts of apprentices or vocational teachers write a didactical Bildungnarrative provides a mass of data and allows more time for interpretation given the work required to transcribe interviews. Thus, the three case studies conducted constitute important complements and elaborations on the explorative vocational education biography of Wolfgang B. and suggest ways of conducting this kind of research within the framework of educational courses making it comparatively effective time-wise.

The most significant aspect of research design has already been mentioned but bears repeating. The narratives need to be narratives of unusual success, in other words, of experiences related to flourishing. This aspect of research design is what sets these kinds of studies apart from most narrative educational research, which focuses more on problems and processes in general. This requires some awareness also because a significant part of narrative inquiry in education is concerned with teacher identity in various ways, whereas the research suggested here focuses on how stories are didactically relevant, i.e. represent a form of articulated, public (in contrast to personal) practical knowledge. Thus, the stories told are not interesting (from this perspective) as statements about the speaker's or writer's personal experiences, skills, capabilities, etc. Rather it is because in the act of speaking or writing them down they transform into a public kind of knowledge about practice but only to the degree that the narrator is capable of telling a story about a concrete event or process or to recount the curriculum of a period of education and the main practices occurring within the framework of it. This does not mean that there is no room for general statements. But any general statement from a practitioner needs to be followed up with a story that constitutes an example of what that particular practitioner understands to be an enactment of those concepts. The reverse is also important, the stories told benefit from being contextualised within some kind of conceptual description as in: 'this is a case of that'. This success aspect is also 
an issue of research ethics. Given the sometimes sensitive matters considered such as conflict resolution or caring for the sick and dying it is a problem in itself to record and publish stories of failure. By focusing on instances of flourishing or success this issue becomes less pressing even if, in the end, it is a matter of judgement, whether or not a particular narrative should be made public.

\section{Narrative research in vocational Bildung didactics}

In the following I will discuss five ways in which narratives can contribute to vocational Bildung didactics bearing in mind that any one narrative can potentially contribute in more than one of these ways. Briefly, these are:

(1) Contributions to the documentation of hitherto unnoticed or unarticulated educational potentials of tasks, vocational curricula, vocational environments and subjects.

(2) Contributions to conceptual development and critical reflection.

(3) A continuous feedback looping back into vocational education practice whereby clusters of exemplary narratives advance the state of practice leading to new narrative variations, this includes direct contributions to the repertoire of vocational practitioners and teachers.

(4) Contributions to the survey and development of 'practice-fields' suggesting a future potential for deeper analysis of how vocational and theoretical environments afford vocational Bildung.

(5) The articulation of various patterns related to vocational Bildung affordances.

These all intersect with the time span of the narratives. This stretches from episodic narratives where the description is closest to enacted affordances of Bildung to whole educational biographies where stories of teachers' actions are combined with descriptions of vocational curricula and experiences of vocational Bildung. I have previously dealt with vocational education biographies and episodic narratives (Tyson 2015a, 2016a), and will focus here, in two of the three narratives, on the more diffuse middle section of the time span, that of educational processes stretching across days, weeks and months.

\section{Vocational Bildung didactics and vocational tasks}

Some case narratives hold the potential to enrich our understanding of what vocational tasks, curricula, environments and subjects can contribute and here I have included examples of a vocational task and a vocational environment. Pursued from this perspective narrative case studies of vocational Bildung can provide knowledge relevant to practitioners in enacting vocational Bildung affordances, relevant to those constructing vocational curricula in deciding what tasks to incorporate in them, what environments to create and what subjects to include. They are also relevant to further research when presented as multiple case studies across one or several tasks, curricula, environments and subjects. Thus, the first case to be discussed taken from Tyson (2015a, 80-86), that of a vocational task, needs further comparative inquiry before it is possible to discern if the Bildung affordance experienced by Mr. B. is one shared by others in relation to it and if so, then how. 


\section{The cube}

The longest single narrative in the whole biographical case of Mr. B. is when he talks about a Christmas gift from his father on his sixteenth or seventeenth birthday. His father, a skilled worker in the metal industry, gave him an iron cube and some files. This cube represents, or at least represented (cf. Stäudel 2010 who is very critical of it), a common task in apprenticeships within many of the metal-related trades where the aim is to make a perfect cube. All sides must be even and all angles correct. Wolfgang goes on to describe how he'swallowed the bait' and decided to try making a perfect cube. In speaking about the process, remembering his experiences, he repeatedly describes interrelated categories of Bildung. One category is his personal development; learning patience, experiencing, and dealing with, frustration, disappointment and anger, developing an increased capacity of will and endurance. Another is the knowledge and know-how directly related to the task. Understanding that the warmth of his hands influence the tools and measurements when doing such precise work, coming to experience degrees of evenness that are almost impossible to imagine together with the skill of being able to achieve them. In relation to warmth, for instance, there is this:

I got a pair of white gloves from him [his father]. 'What am I supposed to do with these?' [And he replied]: 'you're so dirty and you're hands are warm, if you're working with a try-square and are supposed to measure and you hold it in your hand and put it in your pocket it becomes inexact.' And then I got [a lecture] that had to do with temperature and it got so extreme, you can imagine an 18-year old who encounters five degrees of difference in warmth in a tool, its like:'um, ok, so?'

[laughs]

And then you've got this incredibly ingenious person across from you who says: 'Yes but [...] when you went straight from bathing and lay down in the sun, how did that feel? How do you think the metal experiences warmth?' And that just leads to even more go or determination and suddenly you develop a kind of considerateness that to many people seems ridiculous.

All such matters are described as something beyond simple usefulness or capability. He repeatedly talks about his father's pedagogy, how his father again and again would direct his attention to the potential for a wider expanse of knowledge potentially indwelling in the task. Speaking of the cube, Wolfgang was told briefly of the platonic bodies leading to him trying to read Plato. Speaking of the iron and steel of the cube and the tools, he was told of Viking ironworking and the cultural history of it. Finally, Wolfgang also speaks about developing practical judgement, the ability to perceive and evaluate how to do something intelligently:

He told me: 'If you have a cube, then you've got six identical sides and if you're to make a cube from something that isn't even then you have to choose a side that you fit the other sides to.' And I reasoned like a thresher [a way of saying not very intelligently], I figured the side that was the most even, that's the one to start with [...] Then I heard someone say: 'Hey, you can't have a side [as point of departure] that isn't smooth or that isn't completely even. You [...] have to measure [the cube] free hand and look at where the differences are and then you have to calculate all the angles [and proceed from the side] where you have the least amount of work left.'

And then he said:'well [...] this is where you develop judgment, if you go back and take another side, if you judge that side to give you the least amount of work in the future then skip the one you just started working on.' And it's pretty interesting to start your work in the confrontation with all that and then [...] it's easy as hell if you've got a computer that you can input all the measurements into and then it'll do all the calculations for you and tell you where to start. But 
it's not $100 \%$ certain that it has got it right either since well [it depends on how you've thought yourself when inputting the numbers].

The whole process of making the cube took about a year Mr. B. guessed when asked, but of course not full time given that he still went to school. There are several other narratives from the biographical case that fit into this category, all in one way or other considering experiences of Bildung processes and contents. I would tentatively term this a craft-related Bildung-context, i.e. they all share the common denominator of being part of craft environments, tasks and curricula. Other Bildung-related experiences would presumably emerge from similar studies of medical or business environments and, to a lesser degree, between different craft environments. This kind of narrative is also typical of those demonstrating the combination of skill training and Bildung.

One further thing to notice in the narrative (which pushes its didactical relevance beyond a description of this specific task) relates to the initially described interaction, over time, between teaching, environment and curriculum. Wolfgang describes his father's enacted teaching in three ways: first in the way he'lured'Wolfgang to the task getting him to undertake it of his own volition rather than through any demand, second in the way his father didn't provide him with solutions to problems unless queried and thirdly, in his fathers explicit development of the knowledge potential inherent in the task and its materials. Wolfgang also describes the task, tools and materials (i.e. the environment and informal curriculum) as sources of vocational Bildung. This is the strength of biographical descriptions, that they can encompass both descriptions of teachers teaching and descriptions of how this was experienced, i.e. what Billett, among others, calls the enacted and experienced curricula (2011).

Educational biographies are not the only way to conduct such studies. One is through larger scale interviews with teachers, where a small study conducted some years ago and reinterpreted here, can serve as an example of how similar narratives of the interaction between teaching, environment and curriculum emerged. This narrative is taken from a study of a curriculum at a school that has an extensive series of workshops where, apart from regular education, there is also the possibility for students to visit the workshops individually for supportive education, i.e. when they are experiencing various problems in regular class be it social, learning, psychological or other issues. In this particular narrative, one of about 10, the smith speaks about a young girl.

\section{The girl who 'got stuck'}

A long time ago there was a girl at school, as soon as she was in the class room and something new was introduced by the teacher she would 'get stuck' [i.e. be incapable of dealing with the new situation], and then I did the following: for instance, if she got stuck when they were doing maths, then perhaps I sawed with her. And two things were thus done at once: she sawed but at the same time we counted, she does one, I do two and then she's no longer thinking solely about sawing, but also not about counting, there's an interplay between them and she doesn't get stuck on either. And the point with sawing and counting is going from one to the other and back and doing it together so that the movement is mirrored and can't get stuck in itself. Sometimes she would do this with a friend, not just with me, and then one could observe how questions arose between them: did you always get number one, why do you get it and not me? and they begin to think and experiment, and different students do and perceive totally different aspects when they work. So when one takes two 
different things like that then a rhythm enters into it and carries both the counting and the sawing. Another time, for instance, when she was learning to crochet, we forged a long crochet-needle, it was about $1.5 \mathrm{~m}$ long, and then we took a large rope and made the stitches with it and we ended up making a sort of fishing net and after that she could kind flow back into the regular crochet-training. It happened more or less in everything, also in drawing forms, and then we could take a stick, turn the lights off and draw forms with it in the air, both of us together, sometimes in the sandbox with a broomstick, it was all about surprising her in different ways by being totally unexpected so that she forgot that it was actually education and forgot about getting stuck.

Over time her 'stuckness' almost completely dissolved.

It may not be entirely apparent from this story alone, but it becomes so when taken together with other stories from workshop-related vocational environments, that they exhibit a particular abundance of interesting didactical affordances because of the many materials and tools available together with craft-teachers being used to utilising this, i.e. used to thinking about their work in an environmentally embedded way. That the story is a Bildung-related narrative should be clear in that the teacher is actually assisting the student in developing a greater degree of personal autonomy, an autonomy related to herself where such compulsiveness (getting stuck) can be a serious limitation to one's capacity to act. It also presents an interesting addition to the didactical activity that Mr. B. remembers about his father. Here, the teacher uses her knowledge of metal working (i.e. her subject knowledge) together with some articulated principles, rhythm, surprise, mirroring movement and enacts a series of tasks that relate to other subjects (mathematics, crocheting, etc.) as well as to her own and also to the general problem of getting stuck. It is clear that Mr. B.'s narrative is more a part of a VET apprenticeship context, whereas The girl who 'got stuck' is more of a school-related story. However, apprentices who have compulsive behaviour are surely not absent from workplaces, and even though the cube might seem a distant task to introduce in a school environment where time is divided into lessons, the fundamental point I am arguing through these two examples is that a wide-ranging collection of such narratives from various vocational and educational contexts holds the potential to enrich teaching, educational environments and curricula. A significant number of such case histories would provide not only didactical knowledge for practitioners, but also advance our knowledge of educational interventions that might be exceptions or which, if they appeared in a significant number, would suggest new ways of enacting Bildung.

\section{Narratives of vocational Bildung didactics as contributions to conceptual development and critical reflection}

The second matter this kind of research can contribute to is conceptual development and critical reflection. Conceptual development through 'black swan' stories, i.e. stories that in various ways challenge how we think about the possibilities and limitations of vocational education as well as through stories that call attention to phenomena that appear undertheorised. Critical reflection by introducing relevant stories into vocational education and professional development contexts as a way of supporting deliberation and reflection. This is, generally speaking, hardly novel (cf. e.g. Clandinin and Connelly 1995; McDrury and Alterio 2002; McEwan and Egan 1995; Moon 2010), but has, to the extent of my knowledge, not been attempted explicitly with regards to matters of vocational Bildung nor in connection 
with a more systematic approach to narratives of success. Thus, The girl who got 'stuck' can be introduced as a challenge to think about what a workshop-like educational environment has the potential to be and comparable stories that transgress what is often taken for granted as a school environment hold similar potentials (for a more elaborate example cf. Tyson 2016b).

To exemplify, and in order to further contribute to the concept of what vocational Bildung didactics is I will include a third narrative here that specifically relates to this issue. It is taken from a recently completed case study with care professionals, mainly nurses, enrolled in an educational programme at a university in order to get the formal qualifications to teach at the nursing programme in the Swedish upper secondary educational system. It was introduced as part of their didactics course where they were given a brief presentation of narratively articulated vocational Bildung didactics in the context of wise practice. A written description was also handed out including some sample narratives (available from author at request). This is 1 of about 20 narratives collected from that study translated from Swedish to English by me. All participants were informed of this larger study and given the opportunity to refuse participation which one did.

\section{Greta}

This event takes place at a retirement home where I still work. It is about a patient that we have had with us for two years in the wing for patients with dementia. When I saw that the patient was nearing her last hour I felt an obligation to be by her side so that she would not feel alone.

Greta is old and sick. According to the doctors she doesn't have long to live. The only thing Greta can manage to consume is fluid. Greta is religious and appreciates worship. When I enter her room to give her some fluids I notice that Greta is very sad.

Me: Hi dear, are you sad? Is there anything I can to for you?

Greta: I didn't think that I would be afraid of death but I am.

Me: I think it is human to feel a fear of death, I believe most people do. Would you like me to read from the Bible for you? (I hold Greta's hands)

Greta: Yes I would really do. You are so kind and caring, you've always been and it would really bring me joy if you would read to me. But you aren't Christian though?

Me: No I'm not, I'm Muslim but that doesn't matter, just tell me which page you want me to read from or if there's a special prayer that you want us to read together and I will gladly do so as long as it makes you feel better.

Greta: $O$ my friend you are an angel and I already feel much better and not afraid anymore. God has sent you to me and I know that Jesus will receive me when I die and that we shall be reunited with our near and dear.

Greta and me embrace for a long while and then we read from the Bible together. Suddenly, the enrolled nurse [the narrator switches from first to third person here] notices that Greta is silent and has closed her eyes but she continues to read from the Bible and to hold Greta's hand. Greta has passed away peacefully in that moment.

For me it was the only right thing to do to try to get the patient to feel safe and to have peace in her final moments. To ask a patient what he or she wants and what one can do for them is a matter of course since working with elderly is about the needs of patients, both 
physically and emotionally. Since the people in the retirement home often feel lonely it is especially important for enrolled nurses to give them a sense of dignity and the feeling that they are there for them. An important aspect is knowing about the background of patients, it makes it a lot easier to feel empathy and that capacity is central in work with people. In that moment I could relate it to my home culture where it is important that people are not left alone in such processes. People appreciate religion in these situations, death becomes more welcoming for people who are religious and I knew this patient was. Because our interaction went so well I chose to write about it. If one analyses the event from a didactical perspective it was personal experience and the knowledge of the patient's background and my attitude that made the encounter so positive. If I hadn't known the patient as I did I'm not so sure it would have been as positive. But I believe people's attitudes towards situations they end up in play a big part. To enter into different situations even if it is about death can become a positive thing if one has a humanistic way of thinking. Creating a safe environment for another person is a sign of success.

This is one of several stories in the case study that dealt with palliative care situations. In a similar one the nurse narrating the story wasn't religious herself (or at least didn't involve her own spirituality in the narrative) but describes how she would simply sit and listen and be there for the caretaker as well as asking if she wanted her to call a someone from her church, which she did. Juxtaposing such narratives can be a source of critical reflection in both caregiver training and professional development (in the practice field of palliative care) and their relative brevity together with descriptions of actions (mostly conversations) provide sources for reflection on the enactment of wise/caring practice.

The narrative also contributes to the conceptual development of what I (following Claeson 2010) would call a kind of existential Bildung. What makes it didactically relevant is the understanding such narratives can bring, an understanding that informs our sensitivity to situations of death and suffering. Claeson (2010), in her study, writes about a group of women living with chronic diseases where one of her conclusions is that they develop an expertise in existential Bildung and although palliative care and chronic disease are literally existential situations, having begun to develop this aspect of Bildung as concept it seems possible to look for such stories in other vocational fields with less overt existential connotations. This can then be considered more in relation to the other ways in which narrative studies of vocational Bildung didactics are relevant. For instance, collecting a larger number of narratives that describe existential Bildung experiences in a VET context might allow for interesting comparisons of different contexts. It seems likely that gardening, nursing, bookbinding, accounting and taxi-driving would yield somewhat different accounts of existential Bildung. Likewise, certain educational environments might yield richer such stories than others and so forth. Another way that such conceptual development opens the path to further research is that it suggests thinking didactically about those professions where existential Bildung might be a central aspect of vocational competence. As the case study from which Greta is taken suggests, the various caring professions where the concept of vocational phronesis (wise practice or practical wisdom) has perhaps developed the furthest (e.g. Kinsella and Pitman 2012) in combination with a plethora of narrative perspectives (e.g. Charon 2006) could be an interesting field in which to pursue existential Bildung questions. In stories such as Greta the narrative might also go on to yield knowledge that is immediately relevant to practice, which brings us to the next category. 


\section{Narratives of vocational Bildung didactics as contributions to practice}

Narrative research into vocational Bildung didactics takes advantage of the looping effect created by human reflexivity, meaning that practitioners who read of what other practitioners have successfully done can have this enrich their own practice. This can then contribute to the emergence of further narratives that improve on practice creating a positive feedback loop. Considering the stories about The Cube, The girl who got 'stuck' and Greta, they can become part of a practitioners repertoire, a term Schön (1987) uses to characterise how a skilled practitioner relates to a problem or task at hand. An experts' long experience often contains hundreds or even thousands of cases of similar situations that together constitute a more or less articulable repertoire from which a situation is judged. The argument here is that stories such as the ones presented can contribute to the repertoire of both skilled and less skilled practitioners (cf. Tyson 2016a). Such enrichment perhaps sounds easier than it is and it remains an open question how extensively a narrative has to be learned for it to become part of someone's repertoire. The point with regards to Bildung, furthermore, is that such situations are not necessarily very frequent so that the repertoire even of experienced practitioners might be limited unless it is complemented with narratives taken from the repertoire of others.

\section{Narratives as contributions to the survey and development of 'practice-fields'}

In a parallel study (Tyson 2016a), a group of narratives were presented that were all about the same issue, stories of successful conflict resolution enacted by teachers responsible for after-school care for children ages 7-10. Thus, the narratives formed a tighter cluster around one particular issue and context and as further narratives are collected they might begin to form an articulated practice-field: that of conflict resolution relating to various matters confronted by teachers in that context. This can be conflicts when children play, when they refuse to wear certain clothes or cause disturbances when eating, etc. Similarly, the stories about The girl who got 'stuck' and Greta are, by themselves, not much in this regard. But taken together with the half dozen other narratives from the same context of workshop environments it becomes clear that stories such as The girl ... can begin to articulate the Bildungaffordances of the practice-field 'traditional craft workshops', and the story of Greta that of wise practice in helping caretakers with their fear of death as life ends.

The argument is twofold here. First, until we have enough narratives that these Bildungrelated practices become saturated, i.e. where fewer and fewer narratives surface that represent substantially new practices, these fields are largely tacit and unavailable to systematic inquiry. With this I mean that without, e.g. having a variety of narratives relating to the Bildungaffordances of workshop environments we have no idea of how the various claims of vocational Bildung philosophy and experienced practitioners relate to practice. The larger the number of narratives the less it matters here if any one narrative is factually correct or not in all its details. Second, as the number of narratives related to a practice-field grow, it becomes possible to conduct deeper analyses. These could be analyses of discourse and knowledge/ power relationships or comparisons between different theoretical or cultural environments and how they afford vocational Bildung. With the latter I mean, for example, that Greta is couched in a religious or spiritual cultural environment or that The Cube, is enacted in a cultural environment where vocational Bildung and an extensively regulated craft training exists. This 
can be contrasted with narratives of vocational Bildung experiences from craft education that has taken place in environments characterised as deregulated and by on-the-job learning. Perhaps systematic inquiry would provide us with a more empirical foundation for evaluating and creating vocational curricula where various craft tasks are included because they have proven to be unusually rich sources of vocational Bildung in ways that are important in connection with the kinds of competencies and virtues aimed at today in VET.

\section{Narratives holding the potential to articulate patterns relevant to vocational Bildung didactics}

Some narratives have the capacity to surface deeper patterns. With regards to The girl who 'got stuck', the teacher telling the story believes it to be a good example of how to, generally, deal with similar difficulties that students may have. In a sense then it could become a pedagogical-didactical case history in the same way that there is a tradition of case histories in medicine and psychology. Through such case histories we can begin to compare different narratives and thereby develop richer and more adequate practices. Furthermore, both stories of particular educational affordances over time and larger biographical narratives covering whole educational trajectories can demonstrate patterns of vocational curricula that are novel in various ways. Thus, regarding the former I have recently argued, on the basis of a case of developmental work where students from a school in Southern Germany helped construct a hospital and other adjacent facilities in Romania over the course of more than two decades, that it can be understood as a curriculum pattern for certain school-based VET programmes (Tyson 2016b). Regarding the latter, the educational biography of Wolfgang B. suggests a number of different ways in which the concept of 'general Bildung' advocated by Humboldt can be understood in a vocational sense and how this can be understood as a pattern for creating vocational curricula (Tyson, forthcoming).

\section{Concluding remarks}

For the most part the present research is still exploratory and the aim here has been to define its premises conceptually and to differentiate the various intersecting perspectives within which such narratives can be considered. Given the relative novelty of approaching vocational Bildung from an empirical and didactical perspective it seems reasonable to assume that research in the field will continue to be exploratory for some time and that new perspectives, differentiations and critical reflections will become available. To summarise, the main point of this article has been that narratives can contain articulations of practical knowledge related to vocational Bildung didactics that need to be gathered, discussed and analysed systematically. As I have tried to demonstrate this is a wide field of vocational knowledge where my examples are just a small sample of what could be surfaced in this way. And furthermore, it is possible to analyse and discuss such stories from different angles with different, interrelated aims. This suggests a wide potential for further research.

Many of the narratives presented here and elsewhere (Tyson 2015b, 2016a) tend to highlight situations where subject teaching and affording Bildung are entwined in different ways. This is of special significance since there is a continuous tension, especially in VET, between educating for a specific, extrinsic, rationale (becoming skilled) and educating for human flourishing or Bildung where the rationale is intrinsic. Perhaps more than anywhere else this 
is a point where general discussion proves useless to practitioners and repetitive among scholars. What we need is not another affirmation that this tension can become a profitable source of pedagogy but a range of concrete examples covering how, what, when and why. If we cannot devise curricula that make artful use of this tension in order to achieve something that would be impossible if we focused exclusively on the one rather than the other then the argument is moot.

The significance of these arguments and perspectives for VET, although tentative at this exploratory stage, consists in calling attention to the different ways that narratives of vocational Bildung can be interpreted and used for practice and research. For research it provides ways of approaching difficult aspects of didactical practical knowledge. When academic educational research is criticised for being too distant from practice this represents one way of bridging that divide without necessarily giving up academic rigour. It also represents a way of making courses in didactics, at least for people with previous work experience, function in two ways simultaneously. By asking participants to write this kind of narrative they are given the opportunity to contribute from their personal experience and to engage in shared reflection. At the same time these narratives become part of a larger research movement. Similar dual functions can be elicited from professional development work or in various practical/apprenticeships where students/apprentices can be given direct tasks to describe narratively or the task of interviewing someone they consider wise and experienced. This rests on the recognition that if no one tells these kinds of stories there is little access to Bildungrelated aspects of practice, which brings me to a final point: how do we measure vocational Bildung? How can we evaluate competing claims of curricula, environments, didactical practices? A partial but important answer is through this kind of didactical stories. Not one or two, but many, over time, in different circumstances, contexts, etc. It cannot, from this perspective, be about deciding which single institution or teacher is 'the best' but rather about, collectively, moving forward through a more systematic questioning and critique of our own practices through contrasting with that of other's. Thus, I agree here with a recent editorial (2015), where Kelchtermans calls for the development of 'good examples of practice' rather than the development of 'best practice'. Stories of affording vocational Bildung can then begin to serve as a source of public knowledge about Bildung, that personal biographical process that is otherwise perhaps the most difficult part of education to surface and articulate.

\section{Notes}

1. The term vocational is used throughout synonymously with occupational and not as distinct from it.

2. There are different takes on what this includes or denotes, UNESCO $(2005,20)$ lists the capacity for independent learning, working in teams, entrepreneurship and civic responsibility. Brater et al. $(1988,72)$ have a longer list that includes reliability, endurance, patience, exactness, capacity for problem-solving, capacity for improvisation, etc. Not all of these overlap with Bildung but narratives of Bildung experiences that make reference to patience, civic responsibility, etc. provide an empirical source for exploring these matters.

\section{Acknowledgements}

I am thankful for the comments and criticisms of the two anonymous reviewers which were of significant help in revising the article. 


\section{Disclosure statement}

No potential conflict of interest was reported by the author.

\section{ORCID}

Ruhi Tyson (D) http://orcid.org/0000-0002-1573-3229

\section{References}

Barfield, O. 2014. What Coleridge Thought. Oxford: Barfield Press.

Biesta, G. 2013. "Knowledge, Judgment and the Curriculum: On the past, Present and Future of the Idea of the Practical." Journal of Curriculum Studies 45 (5): 684-696.

Billett, S. 2011. Vocational Education. Purposes, Traditions and Prospects. New York: Springer.

Blankertz, H., and A. Gruschka. 1974. "Kollegstufe Nordrhein-Westfahlen als Testfall demokratischer Bildungsreform." [Kolleg-level Education in Nordrhein-Westfahlen as Test Case for Democratic Educational Reform]. Paedagogica Europaea 10 (2): 147-158.

Brater, M., U. Büchele, E. Fucke, and G. Herz. 1988. Berufsbildung und Persönlichkeitsentwicklung [Vocational Bildung and Personality Development]. Stuttgart: Verlag Freies Geistesleben.

Charon, R. 2006. Narrative Medicine. Honoring the Stories of Illness. Oxford: Oxford University Press.

Claeson, L. (2010). “Tid och existentiellt meningsskapande. Kvinnors berättelser om sitt liv med allvarlig sjukdom [Time and Existential Meaning-making. Women's Narratives about Living with Serious Illness]." Doctoral diss., Department of Education, Stockholm University.

Clandinin, D., and M. Connelly. 1995. Teachers' Professional Knowledge Landscapes. New York: Teachers College Press.

Corsten, M., and W. Lempert. 1997. Beruf und Moral [Vocation and Morals]. Weinheim: Deutscher Studien Verlag.

Crawford, M. 2009. The Case for Working with Your Hands. New York: Penguin.

Dormer, P. 1994. The Art of the Maker. London: Thames and Hudson.

Dreyfus, H., and S. Dreyfus. 1986. Mind over Machine. the Power of Human Intuition and Expertise in the Era of the Computer. New York: The Free Press.

Dunne, J. 1993. Back to the Rough Ground. Practical Judgment and the Lure of Technique. Notre Dame: University of Notre Dame Press.

Edding, F., C. Mattern, and P. Schneider, eds. 1985. Praktisches Lernen in der Hibernia-Pädagogik [Practical Learning in the Hibernia Pedagogy]. Stuttgart: Klett-Cotta.

Fintelmann, K. 1990. Hibernia: Modell einer anderen Schule [Hibernia: Model for a Different Kind of School]. Stuttgart: Klett-Cotta.

Flyvbjerg, B. 2001. Making Social Science Matter. Cambridge: Cambridge University Press.

Flyvbjerg, B. 2006. "Five Misunderstandings about Case-study Research." Qualitative Inquiry 12 (2): 219-245.

Gallagher, S. 2013. "An Education in Narratives." Educational Philosophy and Theory 2013: 1-10.

Gessler, L. 1988. Bildungserfolg im Spiegel von Bildungsbiographien [Bildung Achievements Mirrored in Bildung Biographies]. Frankfurt: Peter Lang Verlag.

Gonon, P. 2002. Georg Kerschensteiner: Begriff der Arbeitsschule [Georg Kerschensteiner: The Concept of the Work-school]. Darmstadt: Wissenschaftliche Buchgesellschaft.

Griffiths, M., and G. Macleod. 2008. "Personal Narratives and Policy: Never the Twain?" Journal of Philosophy of Education 42 (S1): 121-143.

Hinchliffe, G. 2004. "Work and Human Flourishing." Educational Philosophy and Theory 36 (5): 535-547.

Kelchtermans, G. 2015. "Learning from 'Good Examples of Practice."' Teachers and Teaching: Theory and Practice 21 (4): 361-365.

Kerschensteiner, G. 1912. "Berufs- oder Allgemeinbildung." [Vocational or General Bildung]. In Grundfragen der Schulorganisation [Basic Issues for School Organisation], edited by G. Kerschensteiner, 24-45. Berlin: B G Teubner. 
Kinsella, E., and A. Pitman, eds. 2012. Phronesis as Professional Knowledge. Practical Wisdom in the Professions. Rotterdam: Sense Publishers.

Klafki, W. 2000. "The Significance of Classical Theories of Bildung for a Contemporary Concept of Allgemeinbildung." In Teaching as a Reflective Practice. The German Didaktik Tradition, edited by I. Westbury, S. Hopmann, and K. Riquarts, 85-108. London: Lawrence Erlbaum Associates.

Lange, U., K. Harney, S. Rahn, and H. Stachowski, eds. 2001. Studienbuch Theorien der beruflichen Bildung [Theories of Vocational Bildung]. Bad Heilbrunn: Klinkhardt.

Larsson, S. 2009. "A Pluralist View of Generalization in Qualitative Research." International Journal of Research \& Method in Education 32 (1): 25-38.

Laszlo, C., J. Sorum Brown, D. Sherman, I. Barros, B. Boland, J. Ehrenfeld, M. Gorham, L. Robson, R. Saillant, and P. Werder. 2012."Flourishing: A Vision for Business and the World." Journal of Corporate Citizenship 2012 (46): 31-51.

McDrury, J., and M. Alterio. 2002. Learning through Storytelling in Higher Education. Using Reflection \& Experience to Improve Learning. London: Kogan Page.

McEwan, H., and K. Egan, eds. 1995. Narrative in Teaching, Learning, and Research. New York: Teacher College Press.

Meyer, M. 2009. Was ist eigentlich Bildungsgangdidaktik? [What is Bildungsgangdidaktik?] Rhino didactics, Zeitschrift für Bildungsgangforschung und Unterricht 29: 1-4.

Moon, J. 2010. Using Story in Higher Education and Professional Development. New York: Routledge.

Rauner, F., and R. Bremer. 2004. "Bildung Im Medium beruflicher Arbeitsprocesse." [Bildung in the Medium of Vocational Work Processes]. Zeitschrift Für Pädagogik 50 (2): 149-161.

Rittelmeyer, C. 2012. Bildung, ein pädagogischer Grundbegriff [Bildung, a Foundational Concept in Pedagogy]. Stuttgart: Kohlhammer.

Schön, D. 1983. The Reflective Practitioner. New York: Basic Books.

Schön, D. 1987. Educating the Reflective Practitioner. San Francisco, CA: Jossey-Bass.

Sennett, R. 2008. The Craftsman. London: Allen Lane: Penguin Books.

Shulman, L. 2004. The Wisdom of Practice. San Francisco, CA: Jossey-Bass.

Stäudel, L. 2010. "Kompetenzorientiert unterrichten: Aufgaben gestalten." [Competence-oriented Education: The Design of Tasks]. Ethik \& Unterricht, 1: 13-16.

Thomas, G. 2010. "Doing Case Study: Abduction Not Induction, Phronesis Not Theory." Qualitative Inquiry 16 (7): 575-582.

Thompson, C. 2006. "Adorno and the Borders of Experience: The Significance of the Nonidentical for a 'Different'Theory of Bildung." Educational Theory 56 (1): 69-87.

Trautmann, M., ed. 2004. Entwicklungsaufgaben im Bildungsgang [Developmental Tasks in the Process of Bildung]. Wiesbaden: Verlag für Sozialwissenschaften.

Tyson, R. 2014. "Aesthetic Bildung in Vocational Education: The Biographical Case of Bookbinding Master Wolfgang B. and His Apprenticeship." Vocations and Learning 7 (3): 345-364.

Tyson, R. 2015. "Vocational Bildung in Action." Licentiate diss., Stockholm University, Department of Education.

Tyson, R. 2015b. “Educating for Vocational Excellence: The Auto/Biographical Exploration of Enacted Craft Pedagogy." Vocations and Learning 8 (2): 229-245.

Tyson, R. 2016a. Pedagogical Imagination and Practical Wisdom: The Role of Success-narratives in Teacher Education and Professional Development. Reflective Practice 17 (4): 456-471.

Tyson, R. 2016b. "When Expectations Clash: Vocational Education at the Intersection of Workplace and School." Interchange 47 (1): 51-63.

Tyson, R. Forthcoming. "What Would Humboldt Say: A Case of General Bildung in Vocational Education?" Uljens, M. 1997. School Didactics and Learning. East Sussex: Psychology Press.

UNESCO. 2005. Towards a Convergence of Knowledge Acquisition and Skills Development. Paris: UNESCO.

Worth, S. 2008. "Storytelling and Narrative Knowing: An Examination of the Epistemic Benefits of Welltold Stories." Journal of Aesthetic Education 42 (3): 42-56. 